Article

\title{
Evaluation of Transplacental Antibody Transfer in SARS-CoV-2-Immunized Pregnant Women
}

\author{
Ching-Ju Shen ${ }^{1, * \mathbb{C}}$, Yi-Chen Fu ${ }^{2}$, Yen-Pin Lin ${ }^{2}$, Ching-Fen Shen ${ }^{3}{ }^{\mathbb{D}}$, Der-Ji Sun ${ }^{4}$, Huan-Yun Chen ${ }^{5}$ \\ and Chao-Min Cheng ${ }^{2, *(\mathbb{B})}$
}

1 Department of Obstetrics and Gynecology, Kaohsiung Medical University Hospital, Kaohsiung Medical University, Kaohsiung 807, Taiwan

2 Institute of Biomedical Engineering, National Tsing Hua University, Hsinchu 300, Taiwan; sandy216621@gmail.com (Y.-C.F.); peggy1240309@gmail.com (Y.-P.L.)

3 Department of Pediatrics, National Cheng Kung University Hospital, College of Medicine, National Cheng Kung University, Tainan 704, Taiwan; drshen1112@gmail.com

4 Department of Obstetrics and Gynecology, Pojen Hospital, Kaohsiung 804, Taiwan; Gummysun@gmail.com

5 Department of Obstetrics and Gynecology, Kaohsiung Chang Gung Memorial Hospital, Kaohsiung 833, Taiwan; B101102082@tmu.edu.tw

* Correspondence: chenmed.tw@yahoo.com.tw (C.-J.S.); chaomin@mx.nthu.edu.tw (C.-M.C.)

Citation: Shen, C.-J.; Fu, Y.-C.; Lin, Y.-P.; Shen, C.-F.; Sun, D.-J.; Chen, H.-Y.; Cheng, C.-M. Evaluation of Transplacental Antibody Transfer in SARS-CoV-2-Immunized Pregnant Women. Vaccines 2022, 10, 101. https://doi.org/10.3390/ vaccines10010101

Academic Editor: François Meurens

Received: 16 November 2021

Accepted: 4 January 2022

Published: 10 January 2022

Publisher's Note: MDPI stays neutral with regard to jurisdictional claims in published maps and institutional affiliations.

Copyright: (C) 2022 by the authors. Licensee MDPI, Basel, Switzerland. This article is an open access article distributed under the terms and conditions of the Creative Commons Attribution (CC BY) license (https:// creativecommons.org/licenses/by/ $4.0 /)$.

\begin{abstract}
Background: Severe acute respiratory syndrome coronavirus 2 (SARS-CoV-2) infection during pregnancy could result in adverse perinatal outcome. Clinical data on the assessment of the immune response in vaccinated pregnant women and subsequent transplacental antibody transfer are quite limited. Objective: To assess maternal and neonatal neutralizing antibody levels against both wildtype and Delta (B.1.617.2) variants after maternal mRNA vaccination. Study Design: This cohort study was conducted 29 pregnant women who were vaccinated at least one dose of Moderna (mRNA-1273) vaccine. Both neutralizing antibody (wildtype and Delta variant) and S1 receptor binding domain IgG antibody levels were evaluated in maternal and cord blood on the day of delivery. Results: Superiority of antibody level was significant in fully vaccinated women compared with the one-dose group (maternal sera, median, $97.46 \%$; cord sera, median, $97.37 \%$ versus maternal sera, median, $4.01 \%$; cord sera, median, $1.44 \%$ ). No difference in antibody level was noted in relation to interval of second immunization to delivery in the two-dose group (95.99\% in 0-2 weeks, $97.45 \%$ in 2-4 weeks, $97.48 \%$ in $4-8$ weeks, $97.72 \%$ in $8-10$ weeks). The most pronounced reduction was observed for the Delta variant. The wildtype neutralizing antibody level of full-vaccinated women was not influenced by the pertussis vaccination. Conclusion: The data underscore the importance of full vaccination in pregnancy and support the recommendation of COVID-19 immunization for pregnant women. The lower level of vaccine-induced neutralizing antibodies for the Delta variant indicates insufficient protection for mother and newborn and highlights the need for development of effective vaccine strategies.
\end{abstract}

Keywords: neutralizing antibody; COVID-19 vaccine; pregnancy; cord blood; Delta variant; maternal immunity

\section{Introduction}

In recent decades, the value of vaccinating pregnant women as a means of protecting both mother and fetus has been well documented [1]. After the mother is vaccinated, antibodies can be delivered before birth via the placenta and after birth via breastfeeding $[1,2]$. The fetal immune system is very different from the newborn immune system, and newborns are more susceptible to microbes and environmental damage $[3,4]$. Vaccination during pregnancy as a means of increasing maternal antibody levels and enhancing passive immunity in infants has been effective against some neonatal infections, such as tetanus $[5,6]$. How much antibody the mother can deliver to the newborn depends on 
the concentration of the mother's antibodies, which is directly related to the time point at which the mother receives the vaccine [7].

Previous studies have shown that antibodies produced by mothers infected with COVID-19 pass through the placenta to the fetus [8,9]. Although the risk and symptoms of pregnant women infected with COVID-19 are the same as those of non-pregnant people $[10,11]$, several studies have found that, compared with age-matched non-pregnant women, pregnant women are more likely to have severe symptoms after being infected with COVID-19, especially when combined with risk factors such as advanced age, preeclampsia, obesity, diabetes, and high blood pressure [11-13]. The risk of neonatal complications such as premature delivery, meconium staining, respiratory distress, and perinatal death increases as well [12-20]. According to the characteristics of different COVID-19 vaccines, the components in the mRNA vaccine would not enter the nucleus of the host cell and remain separated from the host DNA. The mRNA in the vaccine is decomposed by the host cell within a few days, so it is considered more suitable for vaccination during pregnancy [21]. Although a randomized controlled trial study on the safety and adverse reaction characteristics of COVID-19 vaccines did not include pregnant women, as of 4 October 2021, more than 163,000 pregnant women from different ethnic backgrounds in the United States have been vaccinated with either Pfizer-BioNTech (BNT162b2) or Moderna (mRNA-1273) vaccines with no evidence of harm [22,23], or an increase in pregnancy-related complications [24]. Studies have also shown that antibodies produced by mothers infected with COVID-19 during pregnancy can be found in newborn blood, umbilical cord blood, and breast milk, confirming the phenomenon of passive immunity [8,9]. Additionally, a Dutch study found that IgA antibodies in women's breast milk were present for up to ten months after a confirmed maternal infection [25].

Although newborns rely on the transplacental transfer of IgG produced by their mothers to resist the COVID-19 virus, there is not sufficient evidence to support the report $[26,27]$. However, based on previous evidence regarding the vaccination of pregnant women, it should have a positive impact. The aim of this study is to assess the postvaccination immune response (i.e., antibody production) in pregnant women and the correlation between immune response and vaccination time point. Due to increased concern regarding COVID-19 variants, we have included Delta (B.1.617.2) variant-associated results.

\section{Materials and Methods}

\subsection{Study Design and Patients}

This is a prospective study approved by institutional review board of Kaohsiung Medical University Hospital (IRB number: KMUHIRB-SV(II)-20210087). All participants were confirmed negative for SARS-CoV-2 infection with nasopharyngeal swab reverse transcription-polymerase chain reaction on the day of admission and received at least one dose of Moderna (mRNA-1273) SARS-CoV-2 vaccine. Results were obtained from the peripheral blood and umbilical cord blood of 29 mothers on the day of delivery. Newborn blood samples were collected from the umbilical cord after clamping. Of the participants, 25 completed two doses and four had one dose.

All patients in the study had singleton pregnancies without symptoms related to COVID-19 during pregnancy. They had voluntarily vaccinated against COVID-19 with first dose administration between the 27th and 38th week of gestation. The exclusion criteria were age below 20 years, COVID-19 vaccination before pregnancy, preterm labor, and disease with immunosuppressant treatment.

Regarding the protocols of measuring neutralizing antibody and S1 receptor binding domain IgG antibody, we have described the details in Supplementary Materials.

\subsection{Collection of Variables}

The following data were obtained from the medical records: the mother's age, weight, height, race, estimated date of confinement, parity, medical and obstetric history, date of COVID-19 vaccination, date of pertussis immunization, blood drawing dates, deliv- 
ery mode, newborn's birth date, sex, birth weight, and Apgar scores at one and five minutes. Maternal and cord blood neutralizing antibody levels were determined as dependent variables.

\subsection{Statistical Analysis}

The data were analyzed using GraphPad Prism. The correlation between the two different data, maternal and cord blood, were obtained using the Spearman rank correlation coefficient and a Bland-Altman plot. Results of $p<0.05$ were considered to be statistically significant.

\section{Results}

Blood samples were collected from 29 mothers on the day of delivery and from the umbilical cord blood of 29 newborns. Of the pregnant vaccine recipients, 25 completed two doses and four had one dose. Of the four pregnant women who did not complete the two doses of the vaccine, three were due to the shortage of vaccines, and one was because the interval required for the administration was not reached.

\subsection{Participant Characteristics}

Participant demographic and clinical characteristics are presented in Table 1. All mothers confirmed negative for COVID-19 infection by nasopharyngeal swab reverse transcription-polymerase chain reaction results performed on the day of admission. The study population consisted of Asian women who were all vaccinated with the Moderna mRNA-1273 vaccine without severe side effects observed after administration. No maternal, obstetric, or neonatal complications were noted. Median maternal age was 33.21 years (IRQ 31-35) with a median gestational age of 38.55 weeks at the time of delivery. The median gestational age at the first vaccine dose was 28.45 weeks with one woman receiving their first dose in the second trimester, and 28 receiving their first dose in the third trimester.

Table 1. Maternal and newborn demographic and clinical data.

\begin{tabular}{|c|c|}
\hline Variable & Included in the Analysis \\
\hline Age of mothers (years) ${ }^{a}$ & $\begin{array}{l}33.21 *( \pm 3.89 * *) \\
\text { IQR 35-31 }\end{array}$ \\
\hline Parity $^{a}$ & $20(68.97 \% * * *)$ IQR $1-0$ \\
\hline \multicolumn{2}{|l|}{$\geq 1$} \\
\hline $\mathrm{BMI}^{\mathrm{a}}$ & $27.42 *\left( \pm 4.47^{* *}\right)$ IQR $29.6-24.3$ \\
\hline $\begin{array}{c}\text { Weeks of gestation at the first dose of COVID-19 } \\
\text { vaccination (weeks) }{ }^{a}\end{array}$ & $\begin{array}{l}28.45^{*}( \pm 2.64 * *) \\
\text { IQR } 30-27\end{array}$ \\
\hline $\begin{array}{l}\text { Weeks of gestation at the second dose of COVID-19 } \\
\text { vaccination (weeks) } b\end{array}$ & $\begin{array}{l}33.31 *( \pm 2.13 * *) \\
\text { IQR } 34-32\end{array}$ \\
\hline $\begin{array}{l}\text { Interval between the second dose of COVID-19 } \\
\text { vaccination and the collection of blood samples (day } \\
\text { of delivery) (weeks) }\end{array}$ & $\begin{array}{l}5.23 *( \pm 2.04 * *) \\
\text { IQR } 7-4\end{array}$ \\
\hline $\begin{array}{l}\text { Interval between the first dose of COVID-19 } \\
\text { vaccination and the collection of blood samples (day } \\
\text { of delivery) (weeks) }\end{array}$ & $\begin{array}{l}10.00 *\left( \pm 2.45^{* *}\right) \\
\text { IQR } 11-9\end{array}$ \\
\hline Weeks of gestation at delivery (weeks) ${ }^{a}$ & $\begin{array}{l}38.55 *( \pm 1.12 * *) \\
\text { IQR 39-38 }\end{array}$ \\
\hline $\begin{array}{l}\text { Sex of newborn a } \\
\text { Male } \\
\text { Female }\end{array}$ & $\begin{array}{l}11\left(37.93 \% \%^{* * *}\right) \\
18\left(62.07 \%{ }^{* * *}\right)\end{array}$ \\
\hline Weight of newborn $(\mathrm{g})^{a}$ & $\begin{array}{l}3105.69 *\left( \pm 357.07^{* *}\right) \\
\text { IQR 3360-2900 }\end{array}$ \\
\hline
\end{tabular}




\subsection{Sample Characteristics}

Median percentage of inhibition of neutralizing antibodies against wildtype SARS-Co-2 in maternal sera at the time of delivery was significantly lower in those vaccinated with one dose compared to those vaccinated with two doses (40.32\% versus $97.46 \%$, Table 2$)$. For those women who received two-dose vaccinations, median percentage of inhibition of neutralizing antibodies in maternal sera did not differ in relation to the interval of second immunization to delivery (95.99\% in 0-2 weeks, $97.45 \%$ in $2-4$ weeks, $97.48 \%$ in $4-8$ weeks, $97.72 \%$ in $8-10$ weeks, respectively, Table 2$)$. The result was similar in neonatal sera (Rho $=0.5681, p=0.0031$ ) and cord-to-maternal ratio ( $\mathrm{Rho}=0.2389, p=0.2501)$. For women who received a one-dose vaccination, the median percentage of inhibition of neutralizing antibodies for SARS-CoV-2 Delta variant in maternal sera and cord blood were $4.01 \%$ and $1.44 \%$ (Table 2), which were below the cutoff value (30\%) for presence of neutralizing antibodies [27]. In the two-dose immunization group, the inhibition percentage of maternal and cord blood neutralizing antibodies for the Delta variant group were $49.96 \%$ versus $41.86 \%$, $80.72 \%$ versus $57.48 \%, 81.76 \%$ versus $70.60 \%$ at $0-2,2-4,4-8$ weeks from second vaccination time point to delivery respectively (Table 2). The median cord-to-maternal ratio of Delta variant neutralizing antibodies in the two-dose group did not differ in regard to vaccination timing. The inhibition percentage of neutralizing antibodies for the Delta variant was significantly lower in maternal sera and cord blood compared with wildtype $(p=0.0001 \&$ $p<0.0001$, Figure 1). Among cases, the inhibition percentage of neutralizing antibodies for the Delta variant was $29.4 \%$ lower in maternal sera and $37.6 \%$ lower in cord blood. In the two-dose immunization group, all mother-neonatal pairs were positive for SARS-CoV-2 S1 receptor binding domain IgG antibodies, with a positive correlation between maternal sera and cord blood concentration (Rho $=0.7669, p<0.0001$, Figure 2A). Bland-Altman plots of the difference between S1 receptor binding domain IgG antibodies in maternal sera and cord blood against maternal level are presented in Figure $2 \mathrm{~B}(p<0.001)$. Thirteen women received reduced-antigen-content diphtheria-tetanus-acellular pertussis vaccine (Tdap) administration in the third trimester. There was no difference in the percentage of inhibition of neutralizing antibodies between the Tdap group and the non-Tdap group $(p=0.5609$, Figure 3).

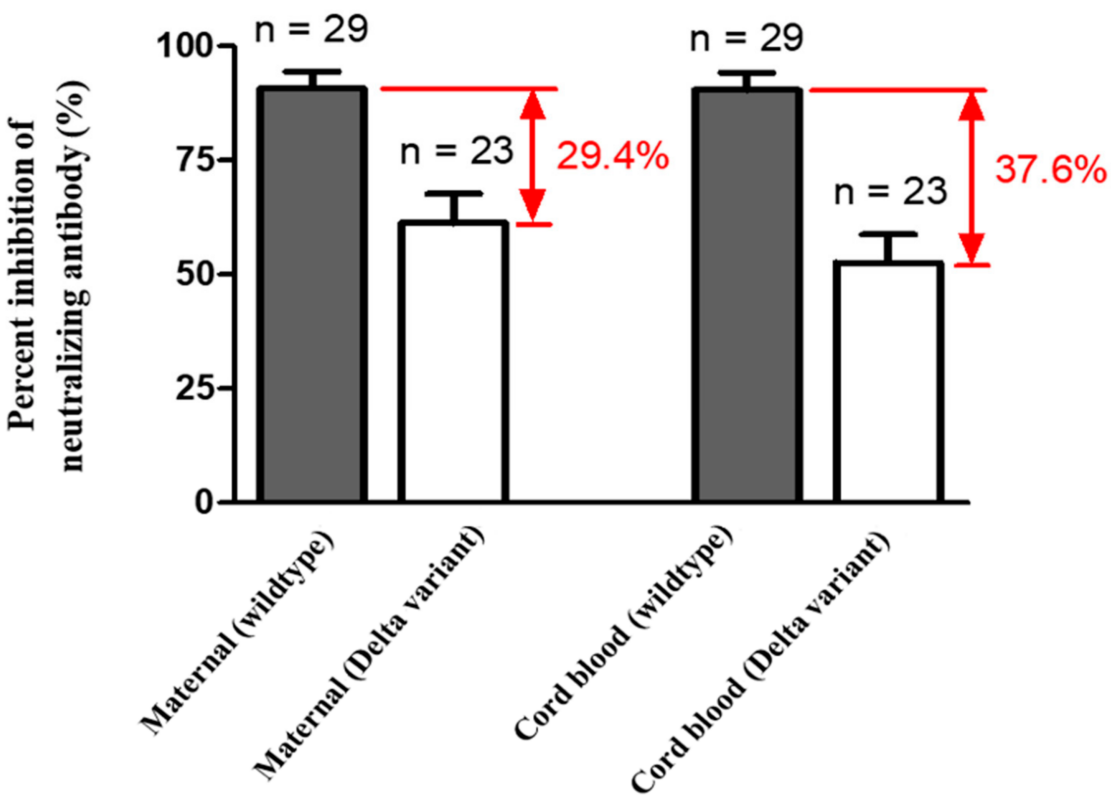

Figure 1. Mean percent inhibition of neutralizing antibodies in maternal and cord blood (wildtype $n=29$ with two dose $n=25$, one dose $n=4$; Delta variant $n=23$ with two dose $n=19$, one dose $n=4 ; p$ value of maternal (wildtype) versus maternal (Delta variant) $=0.0001 ; p$ value of cord blood (wildtype) versus cord blood (Delta variant) <0.0001). 
(A)

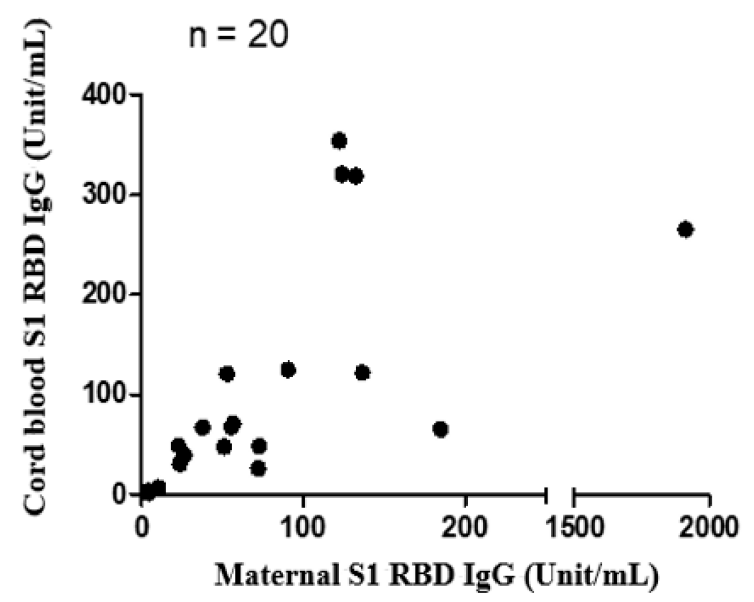

(B)

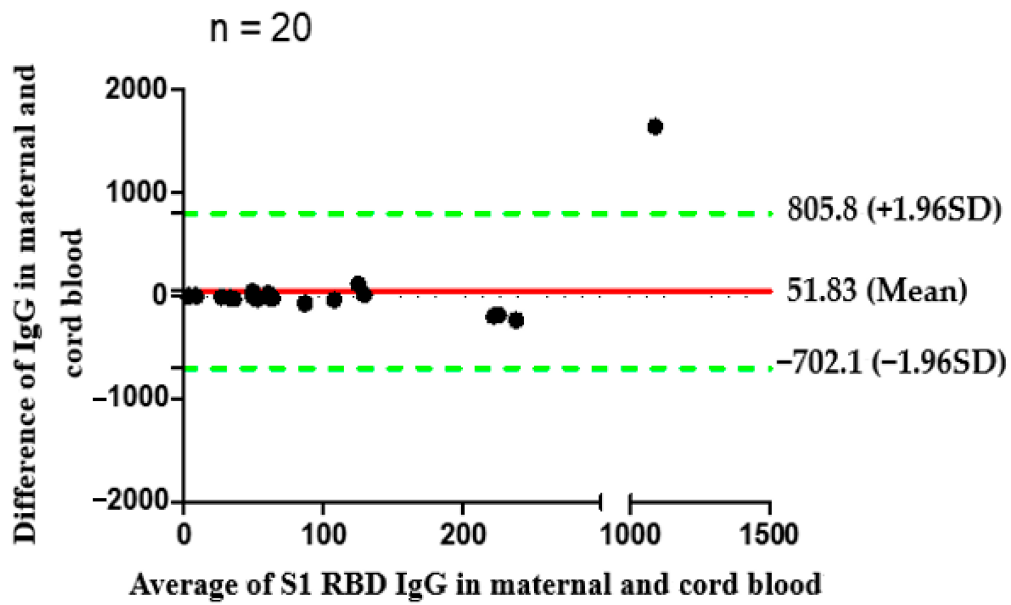

Figure 2. (A) Correlation of S1 receptor binding domain IgG antibodies between maternal and cord blood ( $n=20$, with two dose $n=16$, one dose $n=4$ Rho $=0.7669, p$ value $<0.0001$ ); (B) Bland and Altman plot. The difference of S1 receptor binding domain IgG antibodies in maternal and cord blood in relation to the average of the two $(n=20$, with two dose $n=16$, one dose $n=4)$. Green lines indicate the limits of agreement ( \pm 1.96 standard deviation).

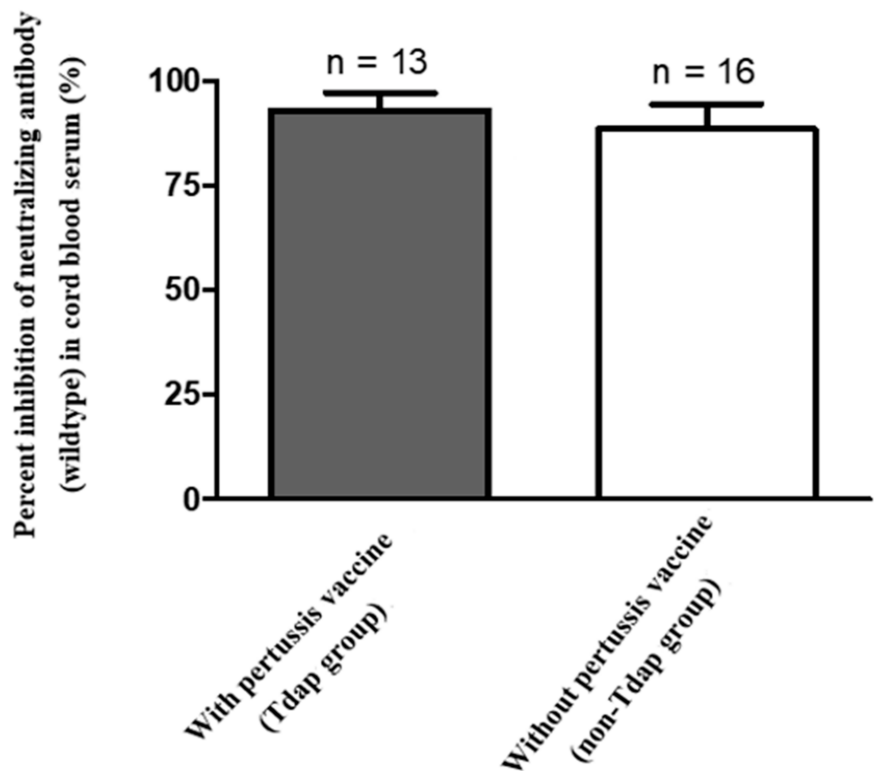

Figure 3. Mean percent inhibition of neutralizing antibodies (wildtype) in cord blood ( $n=29, p$ value $=0.5609$ ). 
Table 2. Summary of neutralizing antibodies (wildtype and Delta variant) in maternal and cord blood.

\begin{tabular}{|c|c|c|c|c|c|c|c|c|c|c|}
\hline Characteristics & $\begin{array}{l}\text { Maternal Neutralizing } \\
\text { Antibody (Wildtype) }\end{array}$ & $\begin{array}{c}\text { Cord Blood } \\
\text { Neutralizing } \\
\text { Antibody (Wildtype) }\end{array}$ & $\begin{array}{l}\text { Cord to Maternal } \\
\text { Ratio (Wildtype) }\end{array}$ & $\begin{array}{l}\text { Maternal Neutralizing } \\
\text { Antibody (Delta Variant) }\end{array}$ & $\begin{array}{l}\text { Cord Blood Neutralizing } \\
\text { Antibody (Delta Variant) }\end{array}$ & $\begin{array}{c}\text { Cord to Maternal } \\
\text { Ratio (Delta Variant) }\end{array}$ & Rho $^{\text {a }}$ & Rho $^{\text {b }}$ & Rho $^{c}$ & Rho $^{d}$ \\
\hline $\begin{array}{l}\text { One-dose group } \\
\text { (median, IQR) }\end{array}$ & $\begin{array}{c}40.32 \% * \\
(51.74-25.28)\end{array}$ & $\begin{array}{c}43.33 \% * \\
(43.74-28.80)\end{array}$ & $\begin{array}{c}1.07^{*} \\
(1.23-0.89)\end{array}$ & $\begin{array}{c}4.01 \% * \\
(7.51-0.87)\end{array}$ & $\begin{array}{l}1.44 \% * \\
(2.16-)\end{array}$ & $\begin{array}{c}0.92 * \\
(1.40-0.86)\end{array}$ & - & - & - & - \\
\hline $0-2$ weeks & $\begin{array}{c}95.99 \%^{1} \\
(96.41-95.58)\end{array}$ & $\begin{array}{c}95.78 \%^{1} \\
(96.38-95.18)\end{array}$ & $\begin{array}{c}0.99^{1} \\
(1.01-0.99)\end{array}$ & $\begin{array}{c}49.96 \%^{1} \\
(51.06-48.87) \\
\end{array}$ & $\begin{array}{c}41.86 \%^{1} \\
(53.26-30.46)\end{array}$ & $\begin{array}{c}0.86^{1} \\
(1.11-0.61) \\
\end{array}$ & - & - & - & - \\
\hline 2-4 weeks & $\begin{array}{c}97.45 \%^{2} \\
(97.61-97.23)\end{array}$ & $\begin{array}{c}97.16 \%^{2} \\
(97.40-96.57)\end{array}$ & $\begin{array}{c}0.99^{2} \\
(1.00-0.99)\end{array}$ & $\begin{array}{c}80.72 \%^{3} \\
(84.74-62.42)\end{array}$ & $\begin{array}{c}57.48 \%^{3} \\
(63.47-47.82)\end{array}$ & $\begin{array}{c}0.78^{3} \\
(0.90-0.75)\end{array}$ & - & - & - & - \\
\hline 4-8 weeks & $\begin{array}{c}97.48 \% \%^{4} \\
(97.74-97.30)\end{array}$ & $\begin{array}{c}97.57 \%^{4} \\
(97.76-97.19)\end{array}$ & $\begin{array}{c}1.00^{4} \\
(1.00-1.00)\end{array}$ & $\begin{array}{c}81.76 \%^{5} \\
(87.51-68.61)\end{array}$ & $\begin{array}{c}70.60 \%^{5} \\
(80.78-61.16)\end{array}$ & $\begin{array}{c}0.92^{5} \\
(0.95-0.87)\end{array}$ & - & - & - & - \\
\hline 8-10 weeks & $\begin{array}{c}97.72 \%^{6} \\
(97.72-97.72)\end{array}$ & $\begin{array}{c}97.30 \%^{6} \\
(97.30-97.30)\end{array}$ & $\begin{array}{c}0.99^{6} \\
(0.99-0.99)\end{array}$ & - & - & - & - & - & - & - \\
\hline
\end{tabular}

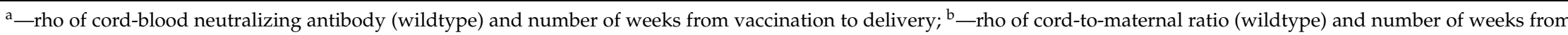
vaccination to delivery; ${ }^{\mathrm{c}}-$ rho of cord-blood neutralizing antibody (Delta variant) and number of weeks from vaccination to delivery; ${ }^{\mathrm{d}}-$ rho of cord-to-maternal ratio (Delta variant) and number of weeks from vaccination to delivery; ${ }^{*}$ case number of one-dose group $=3$; ${ }^{* *}$ case number of two-dose group $=26$; ${ }^{* * *}$ case number of Delta variant group $=20 ;{ }^{1}$, case number $=2 ;{ }^{2}$, case number $=7 ;^{3}$, case number $=6 ;^{4}$, case number $=16 ;{ }^{5}$, case number $=12 ;{ }^{6}$, case number $=1$. 


\section{Discussion}

In this study, we measured SARS-CoV-2 neutralizing antibodies for wildtype and Delta variant in 29 maternal-neonatal pairs following maternal Moderna mRNA-1273 vaccination. Women who received one dose of vaccine had lower neutralizing antibody inhibition percentage compared with those that received two does $(40.32 \%$ versus $97.46 \%$ in maternal sera, $43.33 \%$ versus $97.37 \%$ in cord blood, Table 2 ). According to the results of our study, the cord-to-maternal ratio of neutralizing antibodies is approximately one in fully vaccinated women (Table 2). Therefore, it can be expected that the fetus would obtain protection from passive immunity of transplacental maternal antibodies. IgG antibody level was also consistent with the results of neutralizing antibodies. The S1 receptor binding domain IgG antibody level in the one-dose group was much lower than that in the two-dose group. There were no differences between maternal and cord-blood $\mathrm{S} 1$ receptor binding domain IgG antibody levels. The current results indicate that full maternal immunization has the potential to maximize transplacental antibody transfer to offer adequate seroprotection in young infants. For the Delta variant, the effectiveness of existing vaccines is significantly reduced (Figure 1 \& Table 2) [28]. Our results showed a near absence of maternal and cord-blood neutralizing antibodies for the Delta variant in the one-dose group (Table 2), which is consistent with previous findings indicating that a single dose of Pfizer-BioNTech or AstraZeneca either showed low or no efficiency against the Beta and Delta variants [29]. After a two-dose vaccination, our data indicates that the neutralizing antibodies against the Delta variant significantly increased at the end of two weeks but that level was lower when compared to wildtype (Figure 1). The results of the study are consistent with epidemiological data in the real world [30]. Our results are in accordance with previous reports evaluating the effectiveness of one-dose and two-dose immunizations, showing full vaccination along with clinical outcome. In our study there was no significant difference between the relationship of Tdap vaccination and inhibition percentage of neutralizing antibodies for COVID-19 (Figure 3), supporting the recommendation for COVID-19 vaccine administration during pregnancy.

A previous retrospective cohort study analyzed 503,875 individuals and demonstrated $51 \%$ vaccine effectiveness of Pfizer-BioNTech BNT162b2 vaccine in days 13-24 after one dose [31]. Another nationwide study indicated that estimated vaccine effectiveness during days $14-20$ and days $21-27$ after one dose was $46 \%$ and $60 \%$ for infection, and $57 \%$ and $66 \%$ for symptomatic COVID-19 [31]. Ida et al. observed vaccine effectiveness for healthcare workers in long-term care facilities was even lower $(16 \%, 14$ days after one dose and until second dose) [32]. All studies observed high-level protection against SARS-CoV-2 infection after a second mRNA vaccine immunization [32-35]. These results support the recommendation for a two-dose schedule of SARS-CoV-2 mRNA vaccines for adults without contraindications and previous severe adverse events as a means of providing maximum benefit. For pregnant women, the vaccine's value is not only to protect themselves. Acquired passive immunity provides natural protective effect for young infants against disease. Our study highlighted that the concentration of neutralizing antibodies in the umbilical cord blood reached its highest value 4-8 weeks after maternal complete vaccination, and this result is particularly significant for the Delta variant.

The current global threat to vaccine strategy, immunity propagation, and controlling the spread of disease is virus variants. Although there are variations in different regions, the B.1.617.2 strain was predominant and outcompeted other variants in most countries. The diminishing level of neutralizing antibodies may explain why the Delta variant is more transmissible and why it is less affected by immune protection. The correlation between time from vaccination and breakthrough infection has been studied. A longer time period is associated with decreased vaccine-induced immunity [36] and increased risk of breakthrough infection [37].

For the pregnant women we studied, infection with the Delta variant resulted in a higher proportion of severe-critical disease and preterm births [38,39]. Regarding breakthrough infections from the Delta variant, fully vaccinated pregnant recipients had mild 
symptoms compared to unvaccinated women [37]. No specific type of vaccine can protect all recipients, but those in use have proven effective for reducing the risk of COVID-19 infection, symptom severity, and hospitalization for all variants [40-43]. Our research results showed that even though pregnant women had lower levels of antibodies to the Delta variant after being vaccinated, they should still have partial protection from disease infection. Our results highlight the maternal immunity effect of COVID-19 vaccination and the promising benefit of passive immune transfer to the fetus that reinforces the recommendation for vaccination during pregnancy, especially when Delta variant infections are surging. According to recommendations of American College of Obstetricians and Gynecologists (ACOG), all pregnant women should receive a Tdap vaccine during each pregnancy and an annual influenza vaccine during influenza season [44].

However, there is a lack of information to prove that recommended vaccines administered during pregnancy will not affect the effectiveness of the COVID-19 vaccine, obstetrician-gynecologists and other obstetric caregivers have declined to recommend routine vaccination to pregnant women who have been received COVID-19 vaccine. Our research shows that administering both COVID-19 and pertussis vaccines during pregnancy did not reduce the immunity response of COVID-19 vaccine. This result could offer obstetrician-gynecologists and obstetric care providers more convincing information when making vaccination recommendation for pregnant women.

The strengths of our study are the interested group of participants and neutralizing antibody to evaluate their immune responses. There are still very limited reports on the immune response of pregnant women after COVID-19 immunization. We evaluated and compared the level of neutralizing antibodies against wild type and Delta variants of SARS-CoV-2 produced by pregnant women after vaccination. Our study also disclosed the efficiency of the transferring antibodies produced by the mother to the fetus through the placenta. Since 18 December 2020, the Food and Drug Administration issued an Emergent Use Authorization (EUA) for the Moderna COVID-19 vaccine, the Center for Disease Control and Prevention recommended that pregnant and lactating women have access to the available COVID-19 vaccines. However, pregnant women were excluded from phase-three vaccine efficacy trial, thus data on vaccine efficacy in these populations remains limited. Concerned with the potential for severe illness from SARS-CoV-2 infection during pregnancy, the ACOG recommended that pregnant and recently pregnant women up to 6 weeks postpartum, including pregnant and recently pregnant health care workers, receive a booster dose of COVID-19 vaccine following the completion of their initial COVID-19 vaccine or vaccine series [45]. Regarding the vaccination timing in pregnancy that the booster dose should be administered to achieve the maximum benefit, like pertussis vaccination protocol, further research is needed. Our study indicated the levels of neutralizing antibodies in maternal sera and cord blood were high for 2-10 weeks after vaccination and this result might provide a reference for future booster dose vaccination.

On 24 November 2021, South Africa reported the identification of a new SARS-CoV-2 variant, B.1.1.529, which was later named Omicron, to the World Health Organization (WHO) [46]. In just one month, the Omicron variant caused another surge of infections worldwide. Omicron variant has become the main coronavirus strain in many countries, including the United Kingdom and the United States, at the end of 2022. Consecutive evidence shows that Omicron mutant has higher transmissibility than Delta mutants $[47,48]$, and data from South Africa show that Omicron variant increased the risk of reinfection [49]. Vaccination is expected to protect against severe illness, hospitalizations, and deaths due to infection with the Omicron variant [47]. However, breakthrough infections in people who are fully vaccinated are likely to occur. Therefore, booster vaccination has been widely discussed recently. According to the Pfizer and BioNTech companies' preliminary data reported in December 2021, a third dose induced higher neutralizing antibodies to Omicron, which may help to provide better protection [50]. The ACOG also recommended that all eligible pregnant and recently pregnant individuals receive a COVID-19 booster shot [51]. 
We will continue to follow the immune response of pregnant women after booster dose administration.

This study has several limitations. First, the study size is small, and most participants were vaccinated in the third trimester, and thus conclusion about appropriate timing for better vaccine efficacy has not been determined. Second, the comparison of immunogenicity post COVID-19 vaccination between pregnant and nonpregnant women was not evaluated. Third, for participants who received both COVID-19 and pertussis vaccines, we measured the neutralizing antibodies of SARS-CoV-2, not Tdap-related antigen specific antibodies, so it is impossible to know whether the effectiveness of the pertussis vaccination was affected.

\section{Conclusions}

Immunizing pregnant women is crucial to protect mothers and their offspring from infection. Given the high risk that COVID-19 imposes in pregnancy and reduced neutralizing antibody levels after one dose of mRNA vaccine, pregnant women should receive full vaccination to elicit a high immune response. Lower herd immunity to the Delta variant threatens vaccine strategies; however, the two-dose vaccination still provides a certain degree of protection and decreases severe disease in the real world. Before new vaccines are available, following the existing vaccination guidelines is the best policy. Further studies that examine the interaction between COVID-19 vaccine and other vaccine immunization during pregnancy are necessary.

Supplementary Materials: The following supporting information can be downloaded at: https:/ / www.mdpi.com/article/10.3390/vaccines10010101/s1, SARS-CoV-2 Surrogate Virus Neutralization Test (sVNT). SARS-CoV-2 Neutralizing Antibody Detection (B.1.617.2 Variant). S1 Receptor Binding Domain IgG Antibody Detection.

Author Contributions: Conceptualization, C.-J.S., C.-F.S. and C.-M.C.; methodology, C.-J.S., Y.-C.F. and Y.-P.L.; software, Y.-C.F. and Y.-P.L.; validation, C.-J.S., Y.-C.F., Y.-P.L., C.-F.S., D.-J.S. and H.-Y.C.; formal analysis, C.-J.S., Y.-C.F., Y.-P.L. and C.-M.C.; investigation, C.-J.S., Y.-C.F., Y.-P.L., C.-F.S., D.-J.S. and H.-Y.C.; resources, C.-J.S., C.-F.S. and C.-M.C.; data curation, C.-J.S., Y.-C.F., Y.-P.L., D.-J.S. and H.-Y.C.; writing — original draft preparation, C.-J.S., Y.-C.F. and Y.-P.L.; writing-review and editing, C.-J.S., C.-F.S. and C.-M.C.; visualization, Y.-C.F. and Y.-P.L.; supervision, C.-J.S., C.-F.S. and C.-M.C.; project administration, C.-J.S. and C.-M.C.; funding acquisition, C.-J.S. and C.-M.C. All authors have read and agreed to the published version of the manuscript.

Funding: This study was partially supported by grants from Taiwan's Ministry of Science and Technology (110-2221-E-007-073-MY2 \& 110-2628-E-007-003), Taiwan's National Tsing Hua University (COVID19 project; 110Q2802E1) and Taiwan's Kaohsiung Medical University Hospital (KMUH110-0M42).

Institutional Review Board Statement: Approval was obtained from the Institutional Review Board (IRB) of Taiwan's Kaohsiung Medical University Hospital (IRB number: KMUHIRB-SV(II)-20210087).

Informed Consent Statement: Informed consent was obtained from all subjects involved in the study.

Data Availability Statement: The datasets of this research are available on request to the corresponding author.

Conflicts of Interest: The authors declare no conflict of interest.

\section{References}

1. Munoz, F.M.; Englund, J.A. A step ahead: Infant protection through maternal immunization. Pediatr. Clin. N. Am. 2000, 47, 449-463. [CrossRef]

2. Kachikis, A.; Englund, J.A. Maternal immunization: Optimizing protection for the mother and infant. J. Infect. 2016, 72, S83-S90. [CrossRef] [PubMed]

3. Yu, J.C.; Khodadadi, H.; Malik, A.; Davidson, B.; da Silva Lopes Salles, E.; Bhatia, J.; Hale, V.L.; Baban, B. Innate Immunity of Neonates and Infants. Front. Immunol. 2018, 9, 1759. [CrossRef] [PubMed]

4. Saso, A.; Kampmann, B. Vaccine responses in newborns. Semin. Immunopathol. 2017, 39, 627-642. [CrossRef] [PubMed] 
5. Swamy, G.K.; Garcia-Putnam, R. Maternal immunization to benefit the mother, fetus, and infant. Obstet. Gynecol. Clin. N. Am. 2014, 41, 521-534. [CrossRef] [PubMed]

6. Fouda, G.G.; Martinez, D.R.; Swamy, G.K.; Permar, S.R. The Impact of IgG transplacental transfer on early life immunity. Immunohorizons 2018, 2, 14-25. [CrossRef]

7. Faucette, A.N.; Unger, B.L.; Gonik, B.; Chen, K. Maternal vaccination: Moving the science forward. Hum. Reprod. Update 2015, 21, 119-135. [CrossRef]

8. Zeng, H.; Xu, C.; Fan, J.; Tang, Y.; Deng, Q.; Zhang, W.; Long, X. Antibodies in Infants Born to Mothers with COVID-19 Pneumonia. JAMA 2020, 323, 1848-1849. [CrossRef]

9. Flannery, D.D.; Gouma, S.; Dhudasia, M.B.; Mukhopadhyay, S.; Pfeifer, M.R.; Woodford, E.C.; Triebwasser, J.E.; Gerber, J.S.; Morris, J.S.; Weirick, M.E.; et al. Assessment of Maternal and Neonatal Cord Blood SARS-CoV-2 Antibodies and Placental Transfer Ratios. JAMA Pediatr. 2021, 175, 594-600. [CrossRef]

10. Pettirosso, E.; Giles, M.; Cole, S.; Rees, M. COVID-19 and pregnancy: A review of clinical characteristics, obstetric outcomes and vertical transmission. Aust. N. Z. J. Obstet. Gynaecol. 2020, 60, 640-659. [CrossRef]

11. Donders, G.; Grinceviciene, S.; Haldre, K.; Lonnee-Hoffmann, R.; Donders, F.; Tsiakalos, A.; Adriaanse, A.; de Oliveira, J.M.; Ault, K.; Mendling, W.; et al. ISIDOG Consensus Guidelines on Covid-19 Vaccination for Women before, during and after Pregnancy. J. Clin. Med. 2021, 29, 2902. [CrossRef] [PubMed]

12. Allotey, J.; Stallings, E.; Bonet, M.; Yap, M.; Chatterjee, S.; Kew, T.; Debenham, L.; Llavall, A.C.; Dixit, A.; Zhou, D.; et al. Clinical manifestations, risk factors, and maternal and perinatal outcomes of coronavirus disease 2019 in pregnancy: Living systematic review and meta-analysis. BMJ 2020, 370, m3320. [CrossRef]

13. Agostinis, C.; Mangogna, A.; Balduit, A.; Aghamajidi, A.; Ricci, G.; Kishore, U.; Bulla, R. COVID-19, Pre-Eclampsia, and Complement System. Front. Immunol. 2021, 12, 775168. [CrossRef]

14. Zambrano, L.D.; Ellington, S.; Strid, P.; Galang, R.R.; Oduyebo, T.; Tong, V.T.; Woodworth, K.R.; Nahabedian, J.F., III; AzzizBaumgartner, E.; Gilboa, S.M.; et al. Update-Characteristics of Symptomatic Women of Reproductive Age with LaboratoryConfirmed SARS-CoV-2 Infection by Pregnancy Status-United States, 22 January-3 October 2020. Morb. Mortal. Wkly. Rep. 2020, 69, 1641-1647. [CrossRef] [PubMed]

15. Ellington, S.; Strid, P.; Tong, V.T.; Woodworth, K.; Galang, R.R.; Zambrano, L.D.; Nahabedian, J.; Anderson, K.; Gilboa, S.M. Characteristics of Women of Reproductive Age with Laboratory-Confirmed SARS-CoV-2 Infection by Pregnancy Status-United States, 22 January-7 June 2020. Morb. Mortal. Wkly. Rep. 2020, 69, 769-775. [CrossRef]

16. Martinez-Portilla, R.J.; Sotiriadis, A.; Chatzakis, C.; Torres-Torres, J.; Espino, S.Y.S.; Sandoval-Mandujano, K.; Castro-Bernabe, D.A.; Medina-Jimenez, V.; Monarrez-Martin, J.C.; Figueras, F.; et al. Pregnant women with SARS-CoV-2 infection are at higher risk of death and pneumonia: Propensity score matched analysis of a nationwide prospective cohort (COV19Mx). Ultrasound Obstet. Gynecol. 2021, 57, 224-231. [CrossRef]

17. Maykin, M.M.; Heuser, C.; Feltovich, H.; The Society for Maternal-Fetal Medicine Health Policy Advocacy Committee. Pregnant people deserve the protection offered by SARS-CoV-2 vaccines. Vaccine 2021, 39, 171-172. [CrossRef] [PubMed]

18. Metz, T.D. Maternal and neonatal outcomes of pregnant patients with coronavirus disease 2019 (COVID-19)—A multistate cohort. Am. J. Obstet. Gynecol. 2021, 224, 722-723. [CrossRef]

19. Smith, V.; Seo, D.; Warty, R.; Payne, O.; Salih, M.; Chin, K.L.; Ofori-Asenso, R.; Krishnan, S.; Costa, F.d.S.; Vollenhoven, B.; et al. Maternal and neonatal outcomes associated with COVID-19 infection: A systematic review. PLoS ONE 2020, 15, e0234187. [CrossRef]

20. Turan, O.; Hakim, A.; Dashraath, P.; Jeslyn, W.J.L.; Wright, A.; Abdul-Kadir, R. Clinical characteristics, prognostic factors, and maternal and neonatal outcomes of SARS-CoV-2 infection among hospitalized pregnant women-A systematic review. Int. J. Gynaecol. Obstet. 2020, 151, 7-16. [CrossRef]

21. England, P.H. Coronavirus (COVID-19) Vaccination Information for Public Health Professionals. Updated 30 July 2021. COVID-19: The Green Book, Chapter 14a; 2020. Available online: https:/ /www.gov.uk/government/publications/covid-19-the-green-bookchapter-14a (accessed on 15 November 2021).

22. Prevention CfDCa. V-Safe COVID-19 Vaccine Pregnancy Registry. 2021. Available online: https://www.abtassociates.com/ projects / expanding-v-safe-covid-19-vaccine-pregnancy-registry-0 (accessed on 15 November 2021).

23. Shimabukuro, T.T.; Kim, S.Y.; Myers, T.R.; Moro, P.L.; Oduyebo, T.; Panagiotakopoulos, L.; Marquez, P.L.; Olson, C.K.; Liu, R.; Chang, K.T.; et al. Preliminary Findings of mRNA Covid-19 Vaccine Safety in Pregnant Persons. N. Engl. J. Med. 2021, 384, 2273-2282. [CrossRef] [PubMed]

24. Peretz, S.B.; Regev, N.; Novick, L.; Nachshol, M.; Goffer, E.; Ben-David, A.; Asraf, K.; Doolman, R.; Levin, E.G.; Yochay, G.R.; et al. Short-term outcome of pregnant women vaccinated with BNT162b2 mRNA COVID-19 vaccine. Ultrasound Obstet. Gynecol. 2021, 58, 450-456. [CrossRef] [PubMed]

25. Juncker, H.G.; Romijn, M.; Loth, V.N.; Ruhé, E.J.M.; Bakker, S.; Kleinendorst, S.; de Groot, C.J.M.; Pajkrt, D.; Korosi, A.; van Goudoever, J.B.; et al. Antibodies Against SARS-CoV-2 in Human Milk: Milk Conversion Rates in the Netherlands. J. Hum. Lact. 2021, 37, 469-476. [CrossRef] [PubMed]

26. Zdanowski, W.; Wasniewski, T. Evaluation of SARS-CoV-2 Spike Protein Antibody Titers in Cord Blood after COVID-19 Vaccination during Pregnancy in Polish Healthcare Workers: Preliminary Results. Vaccines 2021, 9, 675. [CrossRef] 
27. Gray, K.J.; Bordt, E.A.; Atyeo, C.; Deriso, E.; Akinwunmi, B.; Young, N.; Baez, A.M.; Shook, L.L.; Cvrk, D.; James, K.; et al. Coronavirus disease 2019 vaccine response in pregnant and lactating women: A cohort study. Am. J. Obstet. Gynecol. 2021, 225, 303.E1-303.E17. [CrossRef]

28. Weekly Epidemiological Update on COVID-19-26 October 2021. 2021. Available online: https://www.who.int/publications/ $\mathrm{m}$ /item/weekly-epidemiological-update-on-covid-19---26-october-2021 (accessed on 15 November 2021).

29. Planas, D.; Veyer, D.; Baidaliuk, A.; Staropoli, I.; Guivel-Benhassine, F.; Rajah, M.M.; Planchais, C.; Porrot, F.; Robillard, N.; Puech, J.; et al. Reduced sensitivity of SARS-CoV-2 variant Delta to antibody neutralization. Nature 2021, 596, 276-280. [CrossRef]

30. Bernal, J.L.; Andrews, N.; Gower, C.; Gallagher, E.; Simmons, R.; Thelwall, S.; Stowe, J.; Tessier, E.; Groves, N.; Dabrera, G.; et al. Effectiveness of Covid-19 Vaccines against the B.1.617.2 (Delta) Variant. N. Engl. J. Med. 2021, 385, 585-594. [CrossRef]

31. Chodick, G.; Tene, L.; Patalon, T.; Gazit, S.; Tov, A.B.; Cohen, D.; Muhsen, K. Assessment of Effectiveness of 1 Dose of BNT162b2 Vaccine for SARS-CoV-2 Infection 13 to 24 Days After Immunization. JAMA Netw. Open 2021, 4, e2115985. [CrossRef]

32. Dagan, N.; Barda, N.; Kepten, E.; Miron, O.; Perchik, S.; Katz, M.A.; Hernán, M.A.; Lipsitch, M.; Reis, B.; Balicer, R.D. BNT162b2 mRNA Covid-19 Vaccine in a Nationwide Mass Vaccination Setting. N. Engl. J. Med. 2021, 384, 1412-1423. [CrossRef]

33. Moustsen-Helms, I.R.; Emborg, H.-D.; Nielsen, J.; Nielsen, K.F.; Krause, T.G.; Molbak, K.; Moeller, K.L.; Berthelsen, A.-S.N.; Valentiner-Branth, P. Vaccine effectiveness after 1st and 2nd dose of the BNT162b2 mRNA Covid-19 Vaccine in long-term care facility residents and healthcare workers-A Danish cohort study. medRxiv 2021. Available online: https://www.medrxiv.org/ content/10.1101/2021.03.08.21252200v1 (accessed on 15 November 2021). [CrossRef]

34. Pilishvili, T.; Gierke, R.; Fleming-Dutra, K.E.; Farrar, J.L.; Mohr, N.M.; Talan, D.A.; Krishnadasan, A.; Harland, K.K.; Smithline, H.A.; Hou, P.C.; et al. Effectiveness of mRNA Covid-19 Vaccine among U.S. Health Care Personnel. N. Engl. J. Med. 2021, 385, e90. [CrossRef]

35. Thomas, S.J.; Moreira, E.D., Jr.; Kitchin, N.; Absalon, J.; Gurtman, A.; Lockhart, S.; Perez, J.L.; Marc, G.P.; Polack, F.P.; Zerbini, C.; et al. Safety and Efficacy of the BNT162b2 mRNA Covid-19 Vaccine through 6 Months. N. Engl. J. Med. 2021, 385, 1761-1773. [CrossRef]

36. Pan, J.; Li, Z.; Wang, L.; Szymanski, J.; Romano, M.; Yin, D.; Wang, A.; Small, T.; Zou, Z.; Li, J.; et al. COVID-19 Neutralizing Antibody Surveillance Testing for Fully Vaccinated Individuals During Delta Variant Spread. medRxiv 2021. Available online: https:/ / www.medrxiv.org/content/10.1101/2021.10.01.21264371v1 (accessed on 15 November 2021). [CrossRef]

37. Mizrahi, B.; Lotan, R.; Kalkstein, N.; Peretz, A.; Perez, G.; Ben-Tov, A.; Chodick, G.; Gazit, S.; Patalon, T. Correlation of SARS-CoV-2 Breakthrough Infections to Time-from-vaccine; Preliminary Study. medRxiv 2021. Available online: https://www.medrxiv.org/ content/10.1101/2021.07.29.21261317v1 (accessed on 15 November 2021). [CrossRef]

38. Seasely, A.R.; Blanchard, C.T.; Arora, N.; Battarbee, A.N.; Casey, B.M.; Dionne-Odom, J.; Sinkey, R.G.; Szychowski, J.M.; Tita, A.T.; Subramaniam, A.; et al. Maternal and Perinatal Outcomes Associated with the Severe Acute Respiratory Syndrome Coronavirus 2 (SARS-CoV-2) Delta (B.1.617.2) Variant. Obstet. Gynecol. 2021, 138, 842-844. [CrossRef] [PubMed]

39. Adhikari, E.H.; SoRelle, J.A.; McIntire, D.D.; Spong, C.Y. Increasing severity of COVID-19 in pregnancy with Delta (B.1.617.2) variant surge. Am. J. Obstet. Gynecol. 2021, 226, 149-151. [CrossRef]

40. Sheikh, A.; McMenamin, J.; Taylor, B.; Robertson, C. SARS-CoV-2 Delta VOC in Scotland: Demographics, risk of hospital admission, and vaccine effectiveness. Lancet 2021, 397, 2461-2462. [CrossRef]

41. Moderna Provides a Clinical Update on the Neutralizing Activity of Its COVID-19 Vaccine on Emerging Variants Including the Delta Variant First Identified in India. 2021. Available online: https:/ /investors.modernatx.com/news-releases/news-releasedetails/moderna-provides-clinical-update-neutralizing-activity-its-covid (accessed on 15 November 2021).

42. Comparative Effectiveness of Moderna, Pfizer-BioNTech, and Janssen (Johnson \& Johnson) Vaccines in Preventing COVID-19 Hospitalizations among Adults without Immunocompromising Conditions-United States, March-August 2021. 2021. Available online: https:/ / www.ncbi.nlm.nih.gov/pmc/articles/PMC8459899/pdf/mm7038e1.pdf (accessed on 15 November 2021).

43. Bergwerk, M.; Gonen, T.; Lustig, Y.; Amit, S.; Lipsitch, M.; Cohen, C.; Mandelboim, M.; Levin, E.G.; Rubin, C.; Indenbaum, V.; et al. Covid-19 Breakthrough Infections in Vaccinated Health Care Workers. N. Engl. J. Med. 2021, 385, 1474-1484. [CrossRef]

44. Immunization, Infectious Disease; Public Health Preparedness Expert Work Group. ACOG Committee Opinion No. 741: Maternal Immunization. Obstet. Gynecol. 2018, 131, e214-e217. [CrossRef] [PubMed]

45. COVID-19 Vaccination Considerations for Obstetric-Gynecologic Care. 2021. Available online: https://www.acog.org/clinical/ clinical-guidance/practice-advisory/articles/2020/12/covid-19-vaccination-considerations-for-obstetric-gynecologic-care (accessed on 3 November 2021).

46. Update on Omicron. 2021. Available online: https://www.who.int/news/item/28-11-2021-update-on-omicron (accessed on 15 November 2021).

47. Omicron Variant: What You Need to Know. 2021. Available online: https://www.cdc.gov/coronavirus/2019-ncov/variants/ omicron-variant.html (accessed on 15 November 2021).

48. He, X.; Hong, W.; Pan, X.; Lu, G.; Wei, X. SARS-CoV-2 Omicron variant: Characteristics and prevention. MedComm 2021, 2, 838-845. [CrossRef]

49. Pulliam, J.R.C.; van Schalkwyk, C.; Govender, N.; von Gottberg, A.; Cohen, C.; Groome, M.J.; Dushoff, J.; Mlisana, K.; Moultrie, H. Increased Risk of SARS-CoV-2 Reinfection Associated with Emergence of the Omicron Variant in South Africa. medRxiv 2021. Available online: https:/ / www.medrxiv.org/content/10.1101/2021.11.11.21266068v2.full.pdf (accessed on 15 November 2021). [CrossRef] 
50. Pfizer and BioNTech Provide Update on Omicron Variant. 8 December 2021. Available online: https://www.pfizer.com/news/ press-release/press-release-detail/pfizer-and-biontech-provide-update-omicron-variant (accessed on 15 November 2021).

51. Covid-19 Vaccine Boosters during Pregnancy. 2021. Available online: https:/ /www.acog.org/covid-19/covid-19-vaccines-toolsfor-your-practice-and-your-patients/boosters-during-pregnancy (accessed on 15 November 2021). 